F. Child Lang. 36 (2009), 1023-1051. (C) 2009 Cambridge University Press doi:I0.1017/So305000909009349 Printed in the United Kingdom

\title{
Usage-based vs. rule-based learning: the acquisition of word order in wh-questions in English and Norwegian*
}

\author{
MARIT WESTERGAARD \\ University of Tromsø/CASTL
}

(Received 20 September 2007. Revised 1о March 2008. First published online 9 March 2009)

ABSTRACT

This paper discusses different approaches to language acquisition in relation to children's acquisition of word order in wh-questions in English and Norwegian. While generative models assert that children set major word order parameters and thus acquire a rule of subject-auxiliary inversion or generalized verb second (V2) at an early stage, some constructivist work argues that English-speaking children are simply reproducing frequent $w h$-word + auxiliary combinations in the input. The paper questions both approaches, re-evaluates some previous work, and provides some further data, concluding that the acquisition of wh-questions must be the result of a rule-based process. Based on variation in adult grammars, a cue-based model to language acquisition is presented, according to which children are sensitive to minor cues in the input, called micro-cues. $\mathrm{V}_{2}$ is not considered to be one major parameter, but several smaller-scale cues, which are responsible for children's lack of syntactic (over-)generalization in the acquisition process.

\section{INTRODUCTION}

Children's acquisition of word order in non-subject wh-questions in English has been studied extensively, and in Ambridge, Rowland, Theakston \& Tomasello (2006) this is described as a topic which 'represents an ideal "test case" for both movement-based generativist accounts and competing constructivist accounts of language acquisition' (p. 520). The present paper takes a fresh look at some child data on word order in wh-questions in English and a dialect of Norwegian, at the same time comparing a generative and a constructivist approach. The Norwegian data discussed are mainly taken from Westergaard (2003), while the English data have been investigated in Rowland \& Pine (2000). Within a generative framework,

[*] Address for correspondence: University of Tromsø/CASTL, 9037 Tromsø, Norway. e-mail : marit.westergaard@hum.uit.no 
Westergaard (2003) argues for the early acquisition of a verb movement rule in Norwegian, generally based on target-consistent production of verb second (V2) as soon as the relevant constructions appear in the child data. Rowland \& Pine (2000), on the other hand, take a constructivist approach to the English data and argue for a distributional learning mechanism that reproduces frequent combinations of wh-words and auxiliaries, e.g. what + did. Some children's failure to produce subject-auxiliary inversion is argued to be due to the target combinations being infrequent in the input.

The paper also provides some new data from the same children on word order in related constructions, e.g. embedded questions and questions with complex wh-phrases. I also present a cue-based model of language acquisition, arguing that children are sensitive to fine distinctions in the input, called micro-cues. This is a generative model in that it argues for the existence of structure and rules in the children's early grammars. But it is also similar to constructivist accounts in that it emphasizes the role of the input. The model is used to account for the attested micro-variation that is found across adult languages with respect to inversion, as well as children's general ability to detect minor syntactic distinctions in the input at an early age.

The paper is organized as follows: the next section provides an overview of word order in wh-questions in English and the Tromsø dialect of Norwegian. I then briefly review the issue of usage-based vs. rule-based learning and some previous accounts of the acquisition of word order in the relevant constructions. In the following section I outline the cue-based model and formulate the micro-cues that are responsible for the word order variation in the target languages. In the remainder of the paper I re-evaluate both the Norwegian and the English child data and conclude that it is difficult to account for the word order of wh-questions without assuming some kind of rule-based process.

THE STRUCTURE OF THE TARGET LANGUAGES

Present-day English displays subject-auxiliary inversion in wh- and yes/ no-questions, as illustrated in ( $\mathrm{I}$ ) and (2). In addition to affecting the auxiliaries HAVE, BE and the modals, this process also applies to the copula BE. Subject-auxiliary inversion is a syntactic requirement, shown by the insertion of dummy Do when there is no other auxiliary present, as in (3).

(I) What will Peter think?

(2) Is Peter the man of your dreams?

(3) What did Peter say?/*What said Peter?

This type of inversion is often called 'residual V2' (Rizzi, I996), as it is considered to be a remnant of a V2 grammar that existed in Old and Middle 
English. In present-day V2 languages, such as Norwegian, German or Icelandic, other clause types also display this word order, typically declaratives. In traditional generative accounts of V2 (e.g. Vikner, I995), it is assumed that the finite verb moves across the subject to the head of the clausal projection (the Complementizer, C), thereby ending up in second position.

With respect to the word order of questions, the difference between English and Norwegian is that, while V 2 is restricted to specific verb types in English (auxiliaries and BE), any lexical verb may appear in front of the subject in Norwegian (see (4)):

(4) Hva sa Peter?

what said Peter

'What did Peter say?'

However, many dialects of Norwegian do not have a strict V2 requirement, allowing non- $\mathrm{V}_{2}$ in certain question types. Vangsnes (2005) gives an overview of the variation across dialects and argues that this is the result of several micro-parameters, mainly related to the type and function of the wh-element. The dialect under investigation in the present paper (Troms $\varnothing$ ) makes a distinction based on the length of the wh-constituent: while monosyllabic wh-elements allow both word orders, the longer ones (disyllabic and full wh-phrases) require $\mathrm{V} 2$, as illustrated in (5) and (6):

(5) Ka les du?/ Ka du les? what read you

'What are you reading?'

(6) Korfor kommer du? / Korfor du kommer?

why come you

'Why are you coming?'

The variation between $\mathrm{V}_{2}$ and non- $\mathrm{V}_{2}$ with the short wh-elements is not random. A study of adult spontaneous speech has shown that there are clear preferences related to subject and verb types, non-V2 typically appearing when the subject is a personal pronoun, and $\mathrm{V}_{2}$ when the subject is an NP and the verb is BE (see Westergaard, 2003). This indicates that information structure plays a role, non- $\mathrm{V}_{2}$ being chosen with informationally given subjects and V2 with new or focused subjects. Examples are provided in (7) and (8):

(7) kor er mitt fly? (INV, file Ole. I7)

where is my plane

'Where is my plane?

(8) kor vi lande henne? (INV, file Ole. I7)

where we land LOC

'Where do we land?' 
Furthermore, subject questions require non- $\mathrm{V}_{2}$ in the form of the relative complementizer som in second position (see (9)). This means that a subject question without som, found in standard Norwegian, is ungrammatical in the dialect.

(9) Kem som kommer?/*Kem kommer?

who som come

'Who is coming?'

Finally, both in Norwegian and English, embedded questions are different from main clause questions in that there is no inversion (see (ro) and ( I I)). However, there are varieties of English which do allow inversion in these cases, e.g. Belfast English and Indian Vernacular English, illustrated in (I2) and (I3) (from Henry, I 995: 106 and Bhatt, 2004: 1020):

(Iо) Jeg vet ikke [hva Peter leser]/*hva leser Peter.

I know not what Peter reads / what reads Peter

'I don't know what Peter is reading.'

(I I) Let me show you [what I am reading] / *what am I reading.

(i2) He didn't say [why had they come].

(I3) I wonder [where does he work].

From an acquisition perspective, this word order variation in adult grammars means that there is quite a bit of detail that must be learned from input: children acquiring English must learn that inversion only applies in questions and not in e.g. declaratives, and furthermore that it is restricted to certain classes of verbs (auxiliaries and BE). Norwegian children growing up in Tromsø must learn that the rule applies in questions with some wh-elements but not others, and that in 'optional' contexts (with the short wh-words), it is dependent on the type of subject (given vs. new information). And both learners of (Standard) English and Norwegian must learn that there is no inversion in embedded questions.

In the next section I briefly discuss the main differences between a generative and a constructivist approach and present some previous accounts of the acquisition of word order in wh-questions.

USAGE-BASED VS. RULE-BASED LEARNING

Within the generative literature it is typically argued that Universal Grammar (UG) provides the language-learning child with the necessary functional structure and constraints, and that all the child needs to do is to learn lexical items and the setting of certain language-specific parameters, e.g. $+/-$ head-final or $+/-$ V2. One of the main reasons for postulating the existence of parameters is the ease and speed of language acquisition; children should only need to be exposed to a few relevant examples to set a 
parameter and thus make major generalizations for their language. Targetconsistent production at a certain level (often 90\%) is then simply taken to be evidence of acquisition. A parameter-setting approach that takes syntactic variation into account (e.g. the restriction on $\mathrm{V}_{2}$ in English) is found in Roeper (I999, 2007), who argues that children in such cases develop competing grammars. The idea of competing parameter settings is also commonly used to explain diachronic language change (e.g. Kroch \& Taylor, I 997).

A constructivist approach, on the other hand, argues that children's early multiword utterances do not reflect the existence of 'big rules', but are the result of a functionally based distributional analysis of the input. Children initially learn item-based chunks and then various 'constructions', where different lexical items may be inserted (Tomasello, 2006). This means that, in children's early production, there is little or no syntactic structure. In this perspective, the input plays a major role, and the relative frequency of forms may account for the order of acquisition as well as children's non-target-consistent utterances (see also Tomasello, 2003).

The acquisition of $\mathrm{V}_{2}$ has been studied extensively (see e.g. Poeppel \& Wexler ( I 993) for German, Jordens ( I 990) for Dutch, Santelmann ( I 995) for Swedish and Westergaard (2003) for Norwegian). Generally, V2 is attested as soon as the relevant constructions appear in the child data, and wh-questions seem to be attested particularly early with this word order. Santelmann ( I 995) finds that, while there are occasional examples of non-target-consistent word order in declaratives in child Swedish, the children's wh-questions are virtually without mistakes. Investigating child German, Clahsen, Penke \& Parodi (I993/94) find that questions with the wh-words was 'what' or wo 'where' plus the copula are attested extremely early with V2 (see (I4)); so early in fact that they consider these questions to be rote-learned at the initial stage.

( I4) wo is de Kugel? (Simone, stage I)

where be.PREs the marble

'Where is the marble?'

English children's acquisition of word order in wh-questions has also been the focus of many studies, and findings vary somewhat (see Ambridge et al. (2006) for an overview). While some studies report that target-consistent word order falls into place as soon as auxiliaries appear in the child data (see e.g. Ingram \& Tyack, I979; Radford, I992), other studies find a certain delay in subject-auxiliary inversion. This delay is normally not random, but seems to affect only some wh-elements or some auxiliaries, as seen in the examples in ( 15 ) and (I6), illustrating both inversion and non-inversion produced in one file by the child Adam from the Brown corpus (CHILDES database, Brown, I973; MacWhinney, 2000). 
(I 5) Why he can't hit? (Adam, 3;4.0I)

(i6) What am I saying? (Adam, 3;4.0I)

Generative accounts typically argue that subject-auxiliary inversion is in place early, and occasional non-target-consistent forms are explained as a result of children's problems with particular wh-items (e.g. adjuncts how and why vs. arguments what and who; see DeVilliers, I99I) or problems with certain auxiliary types (dummy Do or copula BE vs. the rest; see e.g. Santelmann, Berk, Austin, Somashekar \& Lust, 2002).

A constructivist account of the acquisition of wh-questions in English is advocated by Rowland \& Pine (2000, 2003) and Rowland, Pine, Lieven \& Theakston (2003). This approach argues that English-speaking children's early wh-questions are the result of a distributional learning mechanism that reproduces lexically specific combinations of a wh-word and an auxiliary, e.g. what +will. Rowland \& Pine (2000; henceforth R\&P), further argue that wh-questions that appear with correct subject-auxiliary inversion contain wh-word and auxiliary combinations that are frequent in the input, e.g. where +does, while non-target forms appear when children attempt to produce questions with infrequent combinations, e.g. why+can't. R\&P have investigated the data from Adam (see above) and compared this to a sample of the mother's data. They find a correlation between Adam's inverted and non-inverted wh-questions and the frequency of wh-word + auxiliary combinations in the input, and conclude that there is no evidence 'to support the claim that the child [is] operating with a subject-auxiliary inversion rule applied to grammatical categories' (p. I 79).

The role of input frequency is somewhat modified in later work. Ambridge et al. (2006) report on an experimental study which replicates the R\&P finding that children have problems with wh-word + auxiliary combinations rather than these elements individually; e.g. what $+d o$ is more problematic than what + does. Thus, they also argue that children are sensitive to lexically specific combinations and do not have categories such as nouns and verbs in their grammars. However, the children in their study turn out to have problems with different wh-word + auxiliary combinations than Adam, and Ambridge et al. (2006) acknowledge that 'a simple input-frequency based account cannot predict the wh-word+ auxiliary combinations with which children will produce inverted and noninverted questions' (p. 543).

In Ambridge et al. (2006) it is claimed that the studies discussed are specific to English and do not address the full range of wh-questions found in other languages. However, both the generative parameter-based approach and the constructivist usage-based account make claims about the general learning process, and these should in principle be extendable to other languages and other syntactic phenomena. The Norwegian child data 
from Westergaard (2003) and the English data investigated in R\&P are therefore re-evaluated below, and both approaches are questioned. In Westergaard (2008b) I have taken issue with a parameter-setting account of $\mathrm{V}_{2}$, and the present paper therefore focuses on arguments against a constructivist account. Given the word order variation outlined in the previous section, a simple parameter-setting account would predict massive overgeneralization of $\mathrm{V}_{2}$ or subject-auxiliary inversion in early child data. Even an account that assumes competition between conflicting parameter settings seems unable to avoid such a situation. A constructivist account would also predict overgeneralized word order, from highly frequent combinations to less frequent ones (e.g. from main to embedded clauses). Since overgeneralizations will be shown to be virtually non-attested in children's syntax, neither approach can account for the child data. In the next section I therefore outline an alternative approach, a generative model that accounts for word order variation in the input in terms of micro-cues.

\section{A MODEL OF MICRO-CUES}

In order to account for the word order variation across classical $\mathrm{V}_{2}$ languages and English with respect to verb movement, Westergaard (2008b) has developed an extended version of Lightfoot's (I 999, 2006) cue-based approach to language acquisition and change. In the original model, a cue is a piece of structure, provided by $\mathrm{UG}$, which is produced in children's I-language ('internalized language'; see Chomsky, I986; Lightfoot, I 999) on exposure to triggers in the primary linguistic data (PLD). This means that the cue is not a surface string in the input, but a syntactic structure in a child's linguistic system that results from parsing relevant input. In Lightfoot (2006: 86) the cue for V2 syntax is formulated as in (17), a structure with a finite verb in second position (C), which is expressed in all non-subject-initial clauses. Furthermore, it is argued that there must be a UG requirement that the cue is obligatory; otherwise children acquiring a V2 grammar would be unable to generalize this word order to all its contexts.

\section{(I 7) $\mathrm{CP}_{\mathrm{C}}\left[\mathrm{XP}{ }_{\mathrm{C}} \mathrm{V}\right]$}

However, Westergaard $(2008 b)$ discusses word order variation across the Germanic languages and points out that it is not the case that the verb is always in second position. Generally, there is no $\mathrm{V}_{2}$ in embedded contexts, except in Icelandic and Yiddish. Exclamatives also normally exhibit non-V2. And in this paper we have already seen some of the variation that exists in Norwegian and English. Since all these grammars are obviously learnable, children must be paying attention to finer linguistic distinctions than what the cue in (I 7) states. For example, children must be sensitive to 
different clause types, different kinds of initial elements (e.g. long or short wh-words) or different classes of verbs (e.g. auxiliaries and/or BE vs. lexical verbs). Moreover, learners must also distinguish cases where V2 is dependent on information structure.

This means that children must be sensitive to smaller-scale cues; what I have referred to as micro-cues (Westergaard, 2008 $b$; see also Lightfoot \& Westergaard, 2007). First and foremost, learners of Norwegian and English must distinguish between declaratives and questions, since only the latter clause type displays verb movement in English, while there are more complex distinctions between the two in Norwegian dialects. In a syntactic model such as Westergaard $(2008 b)$, where declaratives are considered to be Decl(arative)Ps and wh-questions Int(errogative)Ps, this can be solved by having separate cues for declaratives and questions. Lightfoot's cue for V2 can therefore be reformulated as (I8) and (I9). While (I8) is generally not expressed in the PLD that English children are exposed to, Norwegian children produce this structure in their I-language grammar as a result of the appropriate input.

(I 8) Cue for $\mathrm{V}_{2}$ in declaratives: $\quad \operatorname{DeclP}\left[\mathrm{XP} \operatorname{Decl}^{\circ} \mathrm{V} \ldots\right]$

( 19$)$ Cue for $\mathrm{V}_{2}$ in $w h$-questions: $\quad \operatorname{IntP}\left[w h{ }_{\text {Int }^{\circ}} \mathrm{V} \ldots\right]$

With respect to (I9), matters are somewhat more complex. Since V2 in English is restricted to auxiliaries and $\mathrm{BE}$, this needs to be part of the cue, which could be formulated as (20). Details aside, this cue specifies that only Inflectional elements (here referred to as I) may be found in second position in questions.

(20) Cue for $\mathrm{V}_{2}$ in $w h$-questions (English): $\left.\operatorname{IntP}_{\mathrm{Int}^{\circ}} \mathrm{I} \ldots\right]$

The cue for $\mathrm{V}_{2}$ in Norwegian wh-questions must also be more specific. First and foremost, there must be a distinction between long and short wh-elements, which, according to Westergaard (2009), corresponds to a difference between phrases and heads. Thus, the cue in (2I) specifies that the verb is obligatorily in second position $\left(\mathrm{Int}^{\circ}\right)$ when the wh-element is phrasal. The cue in (22), on the other hand, contains a wh-head which may appear in second position itself. The V2 word order that sometimes occurs in these cases is then considered to be the result of a lower functional head, called the TopP (see also Rizzi, 200I), which is argued to be sensitive to information structure and attracts the verb only when the subject is new or focused information, marked [+FOC] here.

(2 I) Cue for $\mathrm{V} 2$ in questions with long $w h$-elements: $\operatorname{IntP}_{\mathrm{P}}\left[\mathrm{XP}_{[+w h]} \operatorname{Int}^{\circ} \mathrm{V} \ldots\right]$

(22) Cue for $\mathrm{V}_{2}$ in questions with monosyllabic wh-elements: IntP[Int ${ }^{\circ} w{ }_{\text {TopP }}\left[\mathrm{Top}^{\circ} \mathrm{V} \mathrm{SU}[+\mathrm{FOC}] \ldots\right]$ 
USAGE-BASED VS. RULE-BASED LEARNING

TAB LE I. Overview of the Norwegian corpus of child language, Tromsø dialect

\begin{tabular}{lcc}
\hline Name of child & Age & No. of child utterances \\
\hline Ina & I $; 8.20-3 ; 3 . \mathrm{I} 8$ & $20,07 \mathrm{I}$ \\
Ann & I $; 8.20-3 ;$ O.I & I 3, I 29 \\
Ole & I $; 9$. I0-2; I I.23 & I3 485 \\
Total & & 46,685 \\
\hline
\end{tabular}

But how do we account for embedded wh-clauses, which lack $\mathrm{V}_{2}$ in both languages? According to the syntactic model adopted here, different illocutionary force is reflected as different functional structure. Embedded wh-clauses, lacking interrogative force, are thus considered to be bare WhPs, not IntPs. This means that the cues as formulated in (20)-(22) exclude embedded wh-clauses, and nothing needs to be said about them for the languages at hand, Standard English and Tromsø Norwegian. For languages that do display V2 in these clause types (e.g. Belfast English), a separate cue involving the $\mathrm{WhP}$ would have to be formulated.

To summarize, this model is a generative approach that does not seek to explain children's acquisition by reference to one major parameter. Instead, when acquiring inversion in wh-questions, children must acquire a set of smaller-scale cues. This differs from Lightfoot's ( I 999) cue-based approach in that the micro-cues are not themselves provided by UG. Instead, children are assumed to be endowed with categories and structure, and thus the ability to detect fine linguistic distinctions in the input. The formulation of micro-cues in children's grammars then takes place as an interaction between $U G$ and the input. It is important to emphasize that this approach also differs from a constructivist model in that the micro-cues are not surface strings of word combinations, but pieces of (hierarchical) I-language structure that make reference to linguistically relevant distinctions.

\section{A RE-EVALUATION OF THE NORWEGIAN CHILD DATA}

\section{Introducing the data}

The Norwegian child data studied in Westergaard (2003) are taken from a corpus collected in Tromsø (Anderssen, 2006) (see Table I).

Westergaard (2003) focuses on the acquisition of word order in questions with monosyllabic wh-words, where the target grammar allows both $\mathrm{V}_{2}$ and non-V2. The main finding is that both word orders are attested in the child data as soon as relevant constructions appear. Table 2 contains an overview of all complete non-subject wh-questions produced before the age of three. 
TABLE 2. The percentage of $V_{2}$ and non- $V_{2}$ word order in non-subject wh-questions with monosyllabic wh-words, Norwegian corpus of child language

\begin{tabular}{|c|c|c|c|c|c|c|c|}
\hline \multirow[b]{2}{*}{ wh-word } & \multicolumn{2}{|c|}{$\begin{array}{l}\text { INA.OI-23, age } \\
\mathrm{I} ; 8.20-2 ; 10.12\end{array}$} & \multicolumn{2}{|c|}{$\begin{array}{l}\text { ANN.OI-2I, age } \\
\text { I } ; 8.20-3 ; 0.1\end{array}$} & \multicolumn{2}{|c|}{$\begin{array}{l}\text { OLE.OI-22, age } \\
\text { I } ; 9.10-2 ; \text { I I.23 }\end{array}$} & \multirow[b]{2}{*}{ Total } \\
\hline & $\mathrm{V}_{2}$ & Non-V2 & $\mathrm{V}_{2}$ & Non-V2 & $\mathrm{V}_{2}$ & Non-V2 & \\
\hline $\begin{array}{l}\text { ka } \\
\text { 'what' } \\
\text { kor } \\
\text { 'where' } \\
\text { kem } \\
\text { 'who' }\end{array}$ & $\begin{array}{c}35 \% \\
(48) \\
89 \cdot 5 \% \\
(\mathrm{I} 28) \\
72 \cdot 5 \% \\
(2 \mathrm{I})\end{array}$ & $\begin{array}{c}65 \% \\
(89) \\
10.5 \% \\
(15) \\
27.5 \% \\
(8)\end{array}$ & $\begin{array}{c}26 \cdot 4 \% \\
(\text { I } 9) \\
8 \text { I } \% \\
(63) \\
75 \% \\
(9)\end{array}$ & $\begin{array}{c}73 \cdot 6 \% \\
(53) \\
19 \% \\
(15) \\
25 \% \\
(3)\end{array}$ & $\begin{array}{l}\text { (I) } \\
\text { (42) }\end{array}$ & (o) & 263 \\
\hline Total & $\begin{array}{l}64 \% \\
(197)\end{array}$ & $\begin{array}{l}36 \% \\
\left(\begin{array}{ll}\text { I } 12)\end{array}\right.\end{array}$ & $\begin{array}{l}56 \% \\
(9 \mathrm{I})\end{array}$ & $\begin{array}{l}44 \% \\
(7 \mathrm{I})\end{array}$ & $(46)$ & (o) & 517 \\
\hline
\end{tabular}

Moreover, the preference for subject and verb types with the two word orders is very similar to that of the adult data, illustrated in (23) and (24), V2 typically appearing with NP subjects and BE, and non-V2 with pronominal subjects (cf. examples (8) and (9) above). ${ }^{1}$ Based on this, Westergaard concludes that $\mathrm{V}_{2}$ is acquired early and that children have an early sensitivity to information structure.
(23) kor e babyen? (Ina, 2; I.0)
where be.PREs baby.DEF
'Where is the baby?'
(24) ka ho har der \# nedi? (Ina, I ; I o.4)
what she have.PREs there down-in
'What does she have in there?'

Let us question this conclusion. Assuming that $\mathrm{V}_{2}$ is a parameter, acquisition of $\mathrm{V}_{2}$ must mean that the parameter is set correctly. But the children produce both word orders in a principled way-i.e. they immediately discover the relevant distinction in the target language, and there is no indication of grammar competition. From a constructivist view, it could also (rightly) be argued that target-consistent production does not in itself provide evidence for rule-governed behavior. A usage-based account of the findings could argue that the Norwegian children are simply reproducing certain word combinations that are frequent in the input, e.g. kor er 'where is'. In the next section I consider the Norwegian data in such a perspective.

[I] One child (Ole) produces only V2, but all his full wh-questions are of the kind that would also require this word order in the adult data. He also produces certain questions without the wh-word (see examples (32) and (33)), and some of these display inversion while others do not, the choice corresponding to the adult pattern. 


\section{Word combinations and frequencies}

As mentioned above, not just auxiliaries but any lexical verb can appear in second position in Norwegian wh-questions. This means that the number of possible wh-word + verb combinations is considerably higher than in English. This fact alone could make a constructivist approach to these child data less plausible. But that depends of course on how many combinations are ACTUALLY produced at an early stage. R\&P find that during what they call Adam's uninversion period (age 2; I I.I9-3;8. I4), he produces 26 different wh-word + auxiliary combinations with inversion. For comparison, I consider data from only one of the Norwegian children, Ina, who has been recorded slightly longer than the other two (until 3;3) and therefore compares somewhat better with the English data. ${ }^{2}$ In addition to 309 wh-questions with the monosyllabic wh-words (cf. Table 2), Ina produces i 87 further main clause non-subject wh-questions in the corpus, making the total 496. A study of these questions reveals that she produces $63 w h$-word + verb combinations.

But we also need to consider Ina's questions with target-consistent nonV2. Under a constructivist approach, the wh-word would in these cases presumably be considered to form a linguistic collocation with the subject, e.g. ka du 'what you' or kor han 'where he'. In Ina's data there are 40 different wh-word + subject combinations, making the total number of initial twoword combinations I०3 (attested on average 4.82 times, 496/I03). This is of course considerably higher than Adam's 26 target-consistent combinations, but in itself this number cannot be evidence of rule-based acquisition.

Given the number of possible subjects, it seems somewhat odd to assume that a wh-word and a subject should be a collocation that children pay attention to. An alternative approach to these non-V2 cases could be that they are the result of a process where the wh-word alone is stuck onto initial position, while the rest of the sentence remains as before (subject before verb). However, if this were the case, the choice of element(s) to place clause-initially would still have to be dependent on the type of subject. This would be necessary to ensure that wh-words appear clause-initially mainly when the subject is a pronoun, and wh-word+verb combinations when the subject is an NP. That is, the Norwegian children would need to be sensitive to longer combinations than the two first words. This is not in principle problematic for a constructivist account: in order to explain some of the data that do not conform to their expectations, R\&P (p. I78) and Ambridge et al. (2006: 544) suggest that the children in their studies are sensitive to larger formulae in the input, e.g. why don't you or what do you. But for the Norwegian data this would have to hold for virtually ALL the complete (three-word) wh-questions produced, of which there are several

[2] Ina's development also seems to be slightly slower than that of the other two children (see e.g. Westergaard, 2008a). 
hundred different ones attested in the data. To my mind, this seems more than unlikely.

A possible constructivist objection to this might be to say that Ina's grammar DOEs consist of syntactic categories at this stage, but no movement rules. This would make it possible to argue that the grammar contains two schemas for wh-questions, something like $[W H+B E+N P]$, producing $\mathrm{V}_{2}$, and $[W H+$ pronoun $+V]$, resulting in non-V2. However, like adults, the children also produce the respective word orders with other combinations of subject and verb types, dependent on the information structure of the question. Sentence (25), for example, which has non-V2 and an NP subject, is uttered in a situation where løva 'the lion' was mentioned in the immediately preceding context (thus given information), while example (26), which has $V_{2}$ and a pronominal subject, is produced in a situation where the child is pointing, and the subject han der 'he there' is focused.

(25) ka [/] ka løva like å spise mamma? (Ann, 2;6.2 I) what what lion.DEF like.PREs to eat mommie

'Mommie, what does the lion like to eat?'

(26) ka hete han der? (Ina, 2; r 23 )

what is-called he there

'What is He called?'

Another possible objection could be that although Ina's grammar seems to be rule-based when the entire period is investigated, this does not exclude the possibility that there is item-based learning taking place at an early stage. A study of the earliest files (Ina.o I-IO, up to age $2 ; 3.12$ ) reveals that she produces only 72 wh-questions, and as many as $43(59 \cdot 7 \%)$ involve the combination kor + er 'where + is', which indicates that there could be some rote-learned forms at this stage. Nevertheless, Ina produces I 3 distinct initial two-word combinations during this time, attested on average $5 \cdot 54$ times, not very different from the overall average (4.82, see above). Thus, despite the existence of some very frequent combinations, there is no indication that Ina's early grammar is fundamentally different from what it is at later stages.

Finally, the existence of both $\mathrm{V}_{2}$ and non-V2 in the adult grammar means that we cannot detect clear word order mistakes in the Norwegian child data, and it is not possible to study the frequency of input in relation to target and non-target forms, as was done for English. We therefore move on to an investigation of other question types.

\section{Questions with long wh-elements}

In this section we consider the Norwegian children's questions with long wh-elements, which require $\mathrm{V}_{2}$ in the adult language. This means that, in 
TABLE 3. Word order in questions with long wh-elements in Norwegian corpus of child language

\begin{tabular}{|c|c|c|c|c|c|c|}
\hline \multirow[b]{2}{*}{ File (Age) $\backslash w h$-word } & \multicolumn{2}{|c|}{ korsen 'how' } & \multicolumn{2}{|c|}{ korfor 'why' } & \multicolumn{2}{|c|}{ wh-phrases } \\
\hline & $\mathrm{V}_{2}$ & Non-V2 & $\mathrm{V}_{2}$ & Non-V2 & $\mathrm{V}_{2}$ & Non-V2 \\
\hline Ina. $13-27(2 ; 5.25-3 ; 3.18)$ & I & $\circ$ & $7 \mathrm{I}$ & 2 & 2 & I \\
\hline Ann.I7-2I $(2 ; 8.4-3 ;$ O.I $)$ & I & $\circ$ & $\circ$ & I & $\circ$ & $\circ$ \\
\hline Ole. I $6-22\left(2 ; 8.5^{-2} ;\right.$ I I .23$)$ & $\circ$ & $\circ$ & 22 & $\circ$ & $\circ$ & $\circ$ \\
\hline Total & 2 & $\circ$ & 93 & 3 & 2 & I \\
\hline
\end{tabular}

order to be target-consistent, the child grammar must treat the syntax of long and short wh-elements differently. A study of the three children's production reveals that these questions are much less frequent and also appear considerably later than questions with monosyllabic question words.

Nevertheless, Table 3 shows that these question types appear predominantly with target-consistent V2 (97/ го I, 96\%), with the exception of one example in Ann's files and three in Ina's. Ann's parents come from an area north of Tromsø where the dialect marginally allows non-V2 also with the longer wh-elements (see Westergaard, 2009), and they occasionally produce this word order themselves. Ann's one example can therefore be considered a result of this input. Ina's three examples are more difficult to explain, but the fact that they are so rare in her data $(3.9 \%, 3 / 77)$ makes it possible to conclude that Ina nevertheless has a default $\mathrm{V}_{2}$ grammar with long question words. These data thus indicate that the children's grammar is like the adult grammar in that there is a different syntax for different wh-elements.

\section{Embedded questions}

Embedded questions are generally much less frequent than main clause questions in the adult input (see e.g. Westergaard \& Bentzen, 2007). Since embedded questions disallow inversion in Norwegian, this means that children's word order in these clauses could reveal whether their production is rule-governed. If learners are setting a major word order parameter or are sensitive to an obligatory cue such as (I7), one would expect them to initially produce overgeneralization of $\mathrm{V}_{2}$. Similarly, if children are merely paying attention to frequent word combinations in the input, they would also produce inverted word order in embedded questions.

Investigating a large number of English-speaking children up to the age of $5 ; 2$, Diessel \& Tomasello (200I) argue that children's earliest sentential complement utterances do not have any hierarchical structure. The main clause part typically consists of one of a very small number of similar verbs, e.g. 'think' or 'know', and these utterances are argued to be linear 
constructions, where the matrix verb is a formula that is simply stuck onto the beginning of the sentence, which remains an unembedded structure.

An investigation of the Norwegian data initially reveals findings that are similar to what Diessel \& Tomasello attested for English. The three children produce a total of 108 embedded questions in the corpus, most of them (9 I) attested in Ann's data, and only I 3 and 4 in Ina's and Ole's data respectively. While Ann's first example is attested at age 2;2.19 and Ina's as early as I ; I I·22, the majority of these questions appear in the latter half of the recordings. In all these examples there are indeed only three matrix verbs attested, se 'look', vite 'know' and vise 'show', as illustrated in (27)-(29). So perhaps these are simply linear constructions, with a linguistic formula clause-initially, e.g. se her in (27)?

(27) se her [ka Ina gjør]. (Ina, I ; I I.22)

look.IMP here what Ina do.PRES

'Look here what Ina is doing'

Ann vet ikke [kor han er henne]. (Ann, 2;2.19)
Ann know.Pres not where he be.PrEs LOC
'Ann doesn't know where he is.'

(29) skal æ vise \# [korsen man trøkke på knappen]? (Ole, 2; I o. I 5) shall I show how one push.PREs on button.DEF

'Do you want me to show (you) how you push the button?'

However, this cannot be the case, as except for one example in Ina's last file (which is possibly a restart; see Westergaard \& Bentzen, 2007: 280-8I), these embedded questions all appear with non-inverted word order (107/108, 99.1\%). This clearly shows that the Norwegian children distinguish between main and embedded structures.

There is even a set of examples in Ann's data where the matrix clause clearly Is some kind of linguistic formula. These are sentences produced for a very brief period (files Ann.ı8-ı9, age 2;8.24-2;9.I7), where the matrix clause consists of the string vet $d u$ ka? 'do you know what?', which also occurs frequently without an embedded clause in the same files. ${ }^{3}$ The result of this is a curious pattern of double $w h$-words, indicating that vet du ka is treated as a chunk. The resulting construction must nevertheless have some hierarchical structure, causing non-inverted word order in the following clause (see (30) and (3I)). Main clause word order is unattested in these examples.

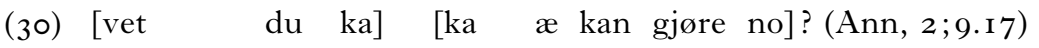
know.Pres you what what I can do now

'Do you know what what I can do now?

[3] In these two files there are altogether i 2 examples with double wh-words, 2 examples with only one $w h$-word, and Io examples of vet du ka? occurring by itself. 
'Do you know what where I have the elephant?

\section{Subject questions and wh-less questions}

Recall from the overview of word order that subject questions always appear with non- $V_{2}$ in the Tromsø dialect, as there is a requirement for the relative complementizer som in second position. A parameter-setting account would again predict overgeneralization of $\mathrm{V}_{2}$ in this case, while a constructivist approach would expect children to reproduce the relatively frequent initial word combinations, kem som or ka som 'who/what som'. Unfortunately, there are few subject questions in the children's production (as in the adult data), twelve in Ina's, seven in Ann's and only one in Ole's data. While all of Ann's questions are target-consistent (the first attested at age $2 ; 6.0$ ), Ole's one example and four of Ina's early ones appear without som, i.e. with $\mathrm{V}_{2}$ (see (32)). This element is even left out in a situation where the child Is imitating the adult, as illustrated in (33).

(32) ka skjedde? (Ina, 2;3.12)

what happen.PAST

'What happened?' Target form: Ka som skjedde?

$$
\begin{aligned}
& \text { nei og nei ka skjer der. (Ole, } 2 \text {; } 1 \text {.5) } \\
& \text { no and no what happens there } \\
& \text { 'Oh no, what is happening there!' } \\
& \text { [= imitating INV saying < nei og nei ka som skjer der }>\text { ]. }
\end{aligned}
$$

These examples show that children do not simply copy frequent word combinations in the input - instead their production seems to be the result of their grammar at the particular stage. However, these examples do not provide evidence for a parameter-setting account either, as it could simply be the case that som, like other functional elements, is somewhat delayed.

Finally, there is one more clause type in the Norwegian child data that should be mentioned, which also indicates that the children are not just reproducing initial word combinations. There is a considerable number of wh-less questions (143) in the child data, especially at an early stage. In these questions, subject-verb word order is completely independent of the presence of the wh-element, as verb movement has taken place across the subject in (34) but not in (35). Note, however, that the word order in these examples does reflect the information structure patterns typically found in the adult language.

(34) er doktoren? (Ole, I; I o.o)

be.PREs doctor.DEF

'(Where) is the doctor?' 
(35) den gjør der? (Ole, I ; I O.০)

That do.Pres there

'(What) is that doing there?'

This re-evaluation of the Norwegian child data shows that neither a traditional parameter-setting account nor a constructivist usage-based approach seems able to explain the data. Given the word order variation in the target language, both approaches would predict a certain amount of overgeneralization in the children's production. However, the children have been shown to immediately produce the target-consistent word order in the right contexts, making linguistically relevant distinctions. I now move on to a discussion of the English child data.

\section{A RE-EVALUATION OF THE ENGLISH CHILD DATA}

\section{Introducing the data}

In this section I reconsider the English child data investigated in R\&P, viz. the production of Adam during the uninversion period, age $2 ;$ I I.28-3;8. I 4 . Also in this section, I focus on a critique of the constructivist approach, showing that it is unable to account for both the original data as well as some further data from Adam's files that I consider here. As mentioned above, R\&P find that Adam produces 26 target-consistent wh-word + auxiliary combinations during the uninversion period. He also produces 20 combinations that are always non-inverted, and only three where both word orders are attested. Investigating a sample of the mother's data, R\&P claim that there is a statistically significant correlation between Adam's production and the frequency of the mother's wh-word and auxiliary combinations, and in Rowland \& Pine (2003: 203) they claim that investigating more of the input gives even clearer results.

$\mathrm{R} \& \mathrm{P}$ have only considered wh-questions involving auxiliaries and disregarded BE. I would argue that it is important to include the copula in order to get a complete picture of children's behavior with respect to inversion. In my re-evaluation of Adam's data, I therefore include his wh-questions with $\mathrm{BE}$, and furthermore, occasional questions with full wh-phrases such as what color or what kind of car, and three instances of main wh-questions introduced by when. I have also counted examples somewhat differently from $\mathrm{R} \& \mathrm{P}$ - as repetitions of the child's own or an adult's previous wh-question have not been excluded. The reason is that very often children do NOT imitate word for word what has been said (see e.g. (33) above). Such examples are an important indication that the child's grammar is not completely target-like. When a child does repeat a sentence in an identical fashion, that is also an interesting fact, in my view. Thus, my numbers are somewhat higher than those found in $\mathrm{R} \& \mathrm{P}$. 
TABLE 4. The percentage of wh-questions with missing verbs/auxiliaries, non-inverted, and inverted word order in Adam.19-36 (age 2; I I.28-3;8.14 )

\begin{tabular}{|c|c|c|c|c|c|c|}
\hline \multirow[b]{2}{*}{ Files } & \multicolumn{3}{|c|}{$\mathrm{BE}$} & \multicolumn{3}{|c|}{ Aux } \\
\hline & Missing & Non-inv. & Inversion & Missing & Non-inv. & Inversion \\
\hline $19-24$ & $\begin{array}{c}60 \cdot 6 \% \\
(152)\end{array}$ & $\begin{array}{c}2 \cdot 0 \% \\
(5)\end{array}$ & $\begin{array}{c}37 \cdot 4 \% \\
(94)\end{array}$ & $\begin{array}{c}87 \cdot 6 \% \\
(254)\end{array}$ & $\begin{array}{c}2 \cdot 4 \% \\
(7)\end{array}$ & $\begin{array}{l}10 \% \\
(29)\end{array}$ \\
\hline $25-30$ & $\begin{array}{c}30 \cdot 4 \% \\
(97)\end{array}$ & $\begin{array}{c}2 \cdot 5 \% \\
(8)\end{array}$ & $\begin{array}{c}67 \cdot 1 \% \\
(214)\end{array}$ & $\begin{array}{c}77 \cdot 2 \% \\
(247)\end{array}$ & $\begin{array}{l}\text { I } 5 \% \\
(48)\end{array}$ & $\begin{array}{c}7 \cdot 8 \% \\
(25)\end{array}$ \\
\hline $31-36$ & $\begin{array}{c}\mathrm{I} 4 \cdot 2 \% \\
(25)\end{array}$ & $\begin{array}{c}2 \cdot 3 \% \\
(4)\end{array}$ & $\begin{array}{c}83.5 \% \\
(\mathrm{I} 47)\end{array}$ & $\begin{array}{c}57 \cdot 0 \% \\
(\mathrm{I} 30)\end{array}$ & $\begin{array}{l}9 \cdot 2 \% \\
(2 \mathrm{I})\end{array}$ & $\begin{array}{c}33 \cdot 8 \% \\
(77)\end{array}$ \\
\hline
\end{tabular}

Table 4 provides an overview of Adam's wh-questions at the three data points identified by R\&P (files I 9-24, 25-30 and 3 I-36). Not unexpectedly, the figures for auxiliaries are similar to R\&P's findings. But the numbers for $\mathrm{BE}$ are very different: wh-questions with missing $\mathrm{BE}$ are much less frequent than questions with missing auxiliaries, and target-consistent word order is correspondingly more frequent. Throughout this period there is a gradual decrease in the former and an increase in the latter, so that at data point 3 , Adam's production is almost completely target-consistent with the copula. Furthermore, non-inversion errors with $\mathrm{BE}$ are virtually non-existent $(2-2.5 \%)$ throughout the investigated period.

These results are also displayed in Figure $\mathbf{I}$, which additionally provides an illustration of the total production of wh-questions. Note that at the end of the period, there are considerably more target-consistent forms than wh-questions with missing verbs $(56 \%$ vs. $38 \%)$, and furthermore, that during this uninversion period, there is no point at which Adam produces more non-inverted than inverted forms.

Nevertheless, the important new finding is that Adam's grammar clearly makes a distinction between auxiliaries and BE. Whenever the copula is included it is virtually always inverted. The development with auxiliaries also seems to illustrate a learning path rather than a child gradually getting better at copying the input: during the first stage, Adam is producing a majority of verbless or auxiliary-less structures, and some of the targetconsistent inverted structures are possibly rote-learned, as they cluster in some frozen formulae such as how do you do it? With respect to the non-target-consistent forms, we see typical U-shaped development. At data point 2, when there is a rise in non-inversion errors, Adam may be realizing that his earlier unanalyzed chunks consist of separate words and he is experimenting with their order. Positive evidence in the input then steers him in the right direction, causing more target-consistent production at data point 3 . 


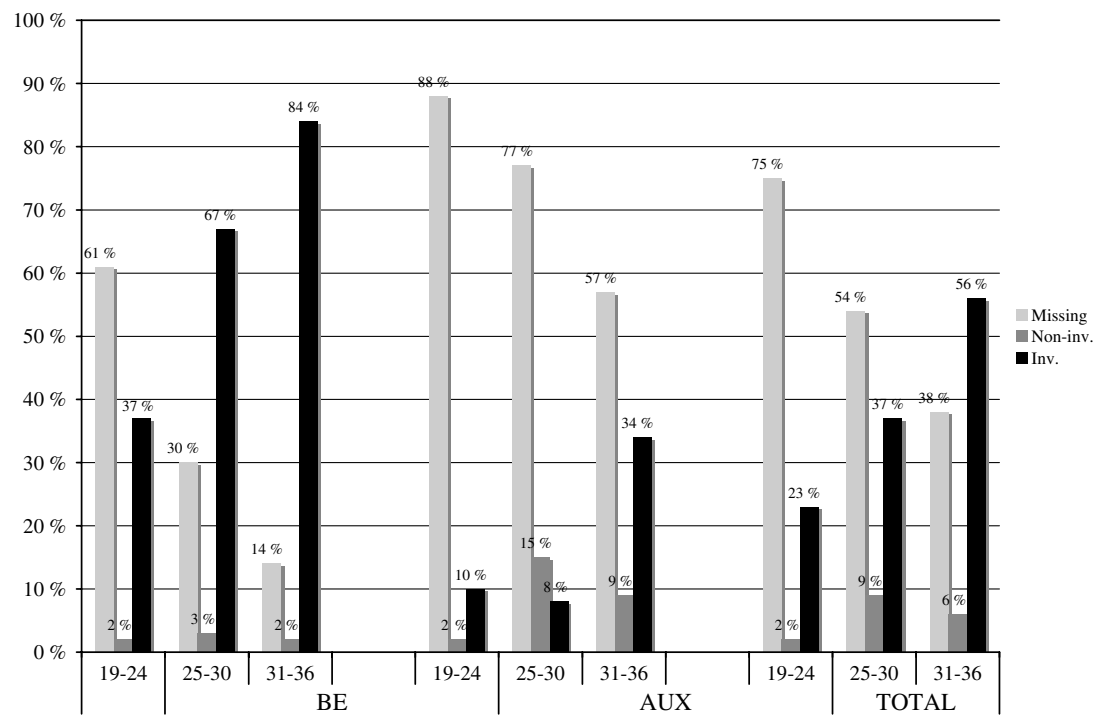

Fig. I. Percentage of wh-questions with missing verbs, non-inverted word order and inverted word order at three data points in Adam.19-36, age 2; I 1.28-3;8. I 4, with BE, Aux and the two categories combined.

A comparison with the Norwegian data also seems relevant here. While the majority of Adam's wh-questions have missing verbs, the number of verbless $w h$-questions is relatively low in the Norwegian corpus, Ina producing $4.8 \%$ (22 out of 455 wh-questions - complete, verbless and wh-less), Ann $3.0 \%$ (5/r69), and Ole only $1 \cdot 6 \%$ ( $1 / 64)$, all occurring in early files. In all cases the missing verb seems to be BE. This indicates that the high number of verbless questions in the English data is related to a problem with auxiliaries. Finally, let us also note that the figures for missing auxiliaries in Adam's data include a number of examples where the main verb is marked as finite (1 $36 / 63 \mathrm{I}, 2 \mathrm{r} \cdot 6 \%$ ), but never inverted (see $(36)$ and (37)).

(36) where firetruck goes? (Adam, 3; O. I I)

(37) what dey said? (Adam, 3;2.09)

\section{Questions with 'long' wh-phrases}

In this section I consider questions with long wh-phrases in Adam's production. As in the Norwegian child data, such questions are much less frequent than those introduced by simple wh-words. Thus, if Adam is getting the word order right only in those questions that have wh-word + auxiliary combinations that are frequent in the input, as argued 
TABLE 5. Word order in questions with long wh-phrases in Adam.19-36, age 2 ; I I.28-3;8. I 4

\begin{tabular}{|c|c|c|c|c|c|}
\hline \multirow[b]{2}{*}{ Files } & \multirow[b]{2}{*}{ Aux missing } & \multicolumn{2}{|c|}{ Non-inversion } & \multicolumn{2}{|c|}{ Inversion } \\
\hline & & $\mathrm{BE}$ & Aux & $\mathrm{BE}$ & Aux \\
\hline $19-24$ & $\circ$ & I & $\circ$ & 4 & $\circ$ \\
\hline $25-30$ & 3 & I & 2 & 25 & $\circ$ \\
\hline $3 \mathrm{I}-3^{6}$ & I & $\circ$ & $\circ$ & 3 & 3 \\
\hline Total & 4 & 2 & 2 & 32 & 3 \\
\hline
\end{tabular}

by R\&P, questions with long wh-phrases should come out wrong most of the time. That is, combinations such as what color $+i$ s or what kind of car + do are predicted to appear non-inverted. Adam's questions with long wh-words during the relevant period are displayed in Table 5 .

As many as 35 of Adam's 43 questions with long wh-phrases appear with target-consistent inversion $(8 \mathrm{I} \cdot 4 \%)$, as illustrated in (38) and (39), only four are non-inverted $(9,3 \%)$, as in $(40)$, while four examples appear without an auxiliary. Again, there seems to be a difference between auxiliaries and $\mathrm{BE}$ : while $\mathrm{BE}$ is correctly inverted $94 . \mathrm{I} \%(32 / 34)$, auxiliaries are inverted only $33.3 \%(3 / 9)$ non-inverted $22 \cdot 2 \%(2 / 9)$ and missing $44 \cdot 4 \%(4 / 9)$.

(38) What kind guns are dose? (Adam, 3; O. I I)

(39) What movie did I saw? (Adam, 3;8.14)

(40) Which bag they were \# huh \# in? (Adam, 3;4.01)

These data clearly weaken R\&P's claim that Adam's inversion pattern is not rule-governed, but only a result of frequent word combinations in the input. It should also be noted that in some of the target-consistent examples, the wh-phrase + auxiliary/BE combinations produced by Adam are either very special or even ungrammatical and presumably not attested in the input at all, e.g. (4I) and (42).

(4I) What kind of monkey is he \# playing da music? (Adam, 3; 5.0 I)

(42) Who glove is dis? (Adam, 3;6.09)

\section{Embedded wh-clauses}

As in Norwegian, there is no inversion in embedded questions in standard English. An investigation of the word order in this clause type may therefore again reveal important properties of the child grammar. Table 6 includes all Adam's embedded structures that are introduced by a wh-word; adverbial clauses as well as embedded questions.

Most of Adam's embedded wh-clauses (75) contain lexical verbs, which do not invert with the subject in main clauses either. In all these cases, 
TABLE 6. Word order in embedded wh-clauses with lexical verbs, auxiliaries and BE, Adam.19-36, age 2; I I.28-3;8.1 4

\begin{tabular}{lcccc}
\hline Files & Non-inv. (Lex. verbs) & Non-inv. (Aux) & Non-inv. (BE) & Inv. (BE) \\
\hline $\mathrm{I} 9-24$ & 2 & $\circ$ & 2 & $\mathrm{I}$ \\
$25-30$ & 38 & 5 & 7 & 2 \\
$3 \mathrm{I}-36$ & 35 & 3 & 5 & 3 \\
Total & $75(72 \cdot 8 \%)$ & $8(7 \cdot 8 \%)$ & I $4(\mathrm{I} 3 \cdot 6 \%)$ & $6(5 \cdot 8 \%)$ \\
\hline
\end{tabular}

Adam produces target-consistent word order, as illustrated in (43), where the subject precedes the verb. In no case does he attempt to invert by adding dummy Do. Thus, these examples indicate that there is no transfer of word order from main clause questions into embedded clauses.

(43) When you touch Paul \# I spank you to pieces. (Adam, 3;3.18)

More telling are examples with copula BE or auxiliaries, which SHOULD invert with the subject in main clauses. Twenty-two of the 28 examples appear without inversion, I 4 with $\mathrm{BE}$ and 8 with auxiliaries, as illustrated in (44) and (45). There are only 6 non-target examples, as in (46), all with BE, again suggesting that Adam's grammar distinguishes between the copula and auxiliaries. I return to a discussion of these examples below.

(44) So we can know [where de mailman is]. (Adam, 3;2.2 I)

(45) I know [what you can do]. (Adam, 3;7.07)

(46) I don't know [what are they]. (Adam, 2; I I.28)

This means that Adam generally produces target-consistent non-inverted word order in embedded wh-clauses (97/103, 94.2\%), which provides support for an analysis that assumes that his grammar has both structure and rules. A possible constructivist objection could be that Adam in these cases shows sensitivity to lexically specific subject-verb combinations, which are of course also very frequent in the input. However, the production of non-target agreement in as many as 12 of the 22 examples with BE or auxiliaries makes such a hypothesis less plausible (see (47) and (48)).

(47) Can I put my head in de mailbox \# so de mailman can know where I are... (Adam, 3;2.2 I)

(48) Once when you was showing me. (Adam 29, 3;4.18)

To summarize so far, I have here considered some further data from Adam's production, wh-questions with $\mathrm{BE}$, with long wh-elements, and wh-elements in embedded contexts. The findings indicate that inversion is generally in place in the former two cases, and target-consistently not in the latter, contrary to what the usage-based analysis would predict. In the next 
TABLE 7. Selection of $\mathrm{wh}+$ Aux combinations that occur inverted or uninverted during the uninversion period and their frequency in the expanded input sample and in Adam's data (adapted from Rowland E Pine, 2003: 204)

\begin{tabular}{|c|c|c|c|c|c|}
\hline $\begin{array}{l}\text { Inverted } \\
w h+\text { Aux } \\
(26 \text { combinations })\end{array}$ & $\begin{array}{l}\text { No. in } \\
\text { input }\end{array}$ & $\begin{array}{c}\text { No. in } \\
\text { Adam's data }\end{array}$ & $\begin{array}{c}\text { Non-inverted } \\
w h+\text { Aux } \\
\text { (20 combinations) }\end{array}$ & $\begin{array}{l}\text { No. in } \\
\text { input }\end{array}$ & $\begin{array}{c}\text { No. in } \\
\text { Adam's data }\end{array}$ \\
\hline \multirow{4}{*}{$\begin{array}{l}\text { where had } \\
\text { where do } \\
\text { what are } \\
\text { what do } \\
\text { etc. }\end{array}$} & 0 & I & \multirow{4}{*}{$\begin{array}{l}\text { how can't } \\
\text { where will } \\
\text { why did } \\
\text { why don't } \\
\text { etc. }\end{array}$} & 0 & 3 \\
\hline & I 4 & 3 & & 5 & 2 \\
\hline & $7 \mathrm{I}$ & I 4 & & 29 & I \\
\hline & I 69 & 27 & & I 67 & 6 \\
\hline
\end{tabular}

section I also dispute R\&P's calculations of the relationship between Adam's data and the input.

\section{Some further issues}

In this section, I question R\&P's calculation of input frequencies in relation to Adam's production of inverted vs. uninverted word order. As mentioned above, R\&P find that Adam produces 26 combinations that are always target-consistent, 20 combinations that are always non-inverted, and only 3 where both word orders are attested. The comparison of Adam's data to frequencies of wh-word + auxiliary combinations in the somewhat larger sample of the mother's data studied in Rowland \& Pine (2003) reveals that the 26 target-consistent combinations are attested 767 times (average $29 \cdot 5$ ), while the 20 non-target-consistent combinations are only attested 247 times (average $12 \cdot 4$ ). A selection of these combinations is provided in Table 7.

However, as R\&P themselves acknowledge, as many as $2 \mathrm{I}$ of these combinations are only attested once in Adam's data ( 13 inverted, 8 non-inverted); thus, there is no chance of overlapping word order in these cases. ${ }^{4}$ These have nevertheless been included in the comparison with the mother's data. $\mathrm{R} \& \mathrm{P}$ (p. I73) also emphasize that the six combinations that most frequently appear inverted in Adam's data (e.g. what + do 27 times, what + are 14 times) not show any overlap. But correct word order is in itself no evidence for the effect of the input, just as it cannot be evidence for the existence of a rule, as I argued above in connection with the Norwegian data. In my view, the interesting finding here is the 20 combinations that are always produced with non-target word order. Disregarding the 8 that only occur once, we are left with 12 combinations. But most of these are also quite rarely attested,

[4] R\&P (p. I73) claim that there are I9 combinations that only appear once, but a count in their own Table 3 (p. I 72 ) reveals that there are in fact $2 \mathrm{I}$. 
generally only 2 or 3 times, and it therefore seems a bit bold to claim that they 'always' appear non-inverted. In fact, there are only three non-targetconsistent combinations which appear more than three times in the child data, what + can (7), why + can't (I O), and why + don't (6).

A second problem with R\&P's calcuation is that as many as $\mathrm{I} 2$ of the 26 combinations that always appear with target-consistent word order involve (non-negative) dummy Do, e.g. what +does or where+did. But I would argue that these combinations are irrelevant as they are unlikely to appear non-inverted in child data. The dummy auxiliary in English is used to support either negation or a question feature. The latter will always appear in inverted position (preceding the subject), while the former will follow the subject. That means that there is no reason to insert dummy Do in the position following the subject unless there is negation; thus, children should not produce positive non-inverted wh-questions with DO, such as what she does like? R\&P have found only one such example in Adam's data, with the combination why + did. However, a closer examination of the context reveals that this is possibly not a true example of this combination, considering Adam's immediately preceding utterance (see (49)). That is, Adam may here be producing an auxiliary-less structure with a finite lexical verb (cf. (36) and (37) above), i.e. why I did (it), attempting to say why did I do (it) - break it?

(49a) what was I did \# break it?

(49b) why I did break it? (Adam, 3;4.0I)

If the I 2 wh-word + auxiliary combinations with dummy Do are excluded from R\&P's list of formulae, then the argument for the difference between the two lists with respect to input frequency is seriously weakened. The reason for this is that these $\mathrm{I} 2$ combinations constitute $80 \cdot 2 \%$ (6I5/767) of the input sample, while the remaining 14 combinations account for less than $20 \%$.

Furthermore, as pointed out by Van Valin (2002: I64), the input sample studied in $\mathrm{R} \& \mathrm{P}$ is clearly too small, as many of the combinations are not attested in the mother's data at all, and it is difficult to see how any predictions could be made based on an occurrence of zero. In the larger sample of Rowland \& Pine (2003), this still holds for 4 target-consistent and ro non-target-consistent combinations. Moreover, there is enormous variation among the different combinations, ranging from i to i 69 examples in the input for the always target-consistent combinations what +have and what $+d o$ respectively. But similar numbers are found in the always non-inverted pattern, from I example for what +should to $\mathrm{I} 67$ for why+ don't. In this perspective, the input frequency of an individual combination has no predictive power, and it seems odd to argue that why + don't (attested I 67 times) is always non-inverted in Adam's data because of lack of input, 
when it is fact attested much more frequently than all but one of the always target-consistent combinations.

In my view, the issues raised here make it necessary to revise the calculation of Adam's data in relation to the input sample. First, the 2 I combinations that are only attested once in Adam's data should be removed from the lists. The I 4 combinations that are not attested in the input at all should also be excluded. And third, we need to exclude the I 2 targetconsistent combinations with dummy DO, as they arguably couldn't appear non-inverted for independent reasons. If we now try to make a comparison between Adam's data and the input sample, the remaining lists would consist of 8 non-target-consistent combinations and only 2 target-consistent ones (what $+i s$, what + are $)$. It seems obvious that a meaningful comparison could no longer be made.

\section{AN ANALYSIS IN TERMS OF MICRO-CUES}

In the previous sections I have re-evaluated both the Norwegian and the English child data and generally concluded that neither a parameter-setting nor a constructivist model such as the one advocated in $\mathrm{R} \& \mathrm{P}$ provides a satisfactory account of the findings. In this section I present an alternative account.

Above, I briefly outlined a model of language acquisition which is based on micro-cues developed in children's I-language grammars as a result of input where these cues are expressed. Thus, children must be endowed with the ability to make fine linguistic distinctions, but the micro-cues themselves need not be given by $\mathrm{UG}$. With respect to $\mathrm{V}_{2}$, these micro-cues reflect the fact that there is considerable variation across languages, dependent on the type of wh-element, the class of verb and the information value of the subject. This micro-variation must be learnable, which means that children at some point in the acquisition process must be sensitive to these distinctions. It is of course logically possible that children first use other learning strategies, e.g. set a major word order parameter or pay attention to frequent word combinations in the input, and only later learn the fine distinctions and/or the deeper structure of the language they are exposed to. However, the child data considered above do not indicate that children go through such phases. Instead they seem to be sensitive to the micro-cues at an early stage. For example, Norwegian children immediately distinguish between long and short (phrasal and head-like) wh-elements as well as the information structure patterns relevant for verb movement. Most English-speaking children also master subject-auxiliary inversion in questions from early on and do not overgeneralize it to other clause types or other verb types (e.g. Radford, I992; Kuczaj \& Maratsos, I983). And both Norwegian- and English-speaking children distinguish between main and embedded contexts. 
One argument that Ambridge et al. (2006) raise against generative accounts is that these claim that English children's problems with inversion is connected either to type of wh-word or to type of auxiliary, while in their own study they find an effect of the combination of wh-words and auxiliaries. According to the cue-based approach, it is not the case that a delay related to certain $w h$-words excludes the possibility of a delay with type of verb. After all, the variation across languages is not limited to one or the other, and it is clear that children learning the different varieties must be sensitive to both types of distinctions. This also seems to be the case in Adam's development, which we now return to.

First of all, it is clear that Adam's grammar during the uninversion period makes a distinction between auxiliaries and the copula ( $c f$. Figure I). That is, auxiliaries are more often missing, and inversion falls into place much later than with BE. Note also that in those cases where inversion is overgeneralized, in embedded clauses, this only affects BE (cf. Table 6). Early target-consistent word order with the copula cannot be the result of rote-learned forms only, as there are many examples in the data that do not belong to the typical formulae of frequent word combinations, e.g. the ones with long wh-phrases. The distinction between BE and auxiliaries is linguistically relevant and also found in other languages, e.g. in the Norwegian adult data, where inversion is clearly preferred with BE, but not auxiliaries. This means that Adam's grammar is at some point assuming even finer micro-cues than the target grammar.

Second, as has been noted by R\&P themselves and many others (e.g. Van Valin, 2002), there is also a distinction between different wh-elements in Adam's production, notably why and other wh-words, attested also in data from other children. That is, Adam's grammar generally does not display inversion in why-questions $(88 \cdot 1 \%, 52 / 59)$; there are even non-inverted examples with $\mathrm{BE}$ in these cases. In comparison, non-inversion with the question words what and where appear in only $3.4 \%(24 / 7$ I 3$)$ and $4.0 \%$ (7/I73) of the data. According to Table 4, Adam produces a total of 76 non-inverted examples with auxiliaries and I 7 with BE. As many as $55.3 \%$ $(42 / 76)$ of the former appear in questions with why, and $58.8 \%$ (10/1 7$)$ of the latter. Many explanations for the special status of why have been explored (see e.g. Ambridge et al., 2006). I will not contribute to this discussion, but simply point out that this distinction must be a linguistically relevant one, as why is syntactically different from other wh-elements also in other languages, e.g. Italian (see e.g. Poletto \& Pollock, 2004). Adam's behavior is thus not unlike that of Norwegian children, who have different V2 grammars for different wh-elements at an early age.

This means that Adam's grammar at the universion stage is a SMALLER V2 grammar than that of adult English. The micro-cue model may thus be related to the common observation that children are conservative learners 
(for a recent discussion, see Snyder, 2007). That is, the micro-cues are not only responsible for the lack of overgeneralization in language acquisition, they may also cause a delay in cases where generalization would result in target-consistent production. Micro-cues thus prevent English-speaking children from overgeneralizing $\mathrm{V}_{2}$ from questions to declaratives or from auxiliaries to lexical verbs. But they also cause (some) children to be even more careful, e.g. Adam: having learned V2 with BE, he does not generalize to auxiliaries, and having learned $\mathrm{V}_{2}$ with what, he does not generalize to linguistically distinct wh-words, such as why. Given the view of V2 as a set of smaller-scale cues (rather than a major parameter), it is not surprising that the full grammar of inversion does not fall into place immediately. It is also not unlikely that individual children may acquire the micro-cues in different orders. This would then explain the sometimes diverging findings across studies, since children may simply have different acquisitional paths.

Two further properties of Adam's grammar need to be explained. First, there is the often noted fact that negated auxiliaries generally do not invert (see Ambridge et al. (2006) and references cited there). In R\&P's list of wh-word +auxiliary combinations that consistently appear with non-inverted word order in Adam's data, 7 of the 20 combinations contain a negated auxiliary ( 3 with DO, 4 with modals), making up $43 \cdot 3 \%$ of the total $(26 / 60)$. Of the 26 combinations that consistently appear with inversion, on the other hand, none are negated. The discussion of the role of dummy Do in Adam's grammar in the previous section may now shed some new light on why non-inversion errors are frequent with negated forms. Recall that I argued that there is no need to insert the dummy auxiliary unless it is in inverted position. However, there Is a reason to insert Do in the position following the subject when there is negation that needs to be supported. This could possibly also account for the high frequency of negated modals in the non-target-consistent forms, as the modals may also have been inserted mainly to support negation. In a positive question, on the other hand, the modals (and DO, as argued above) may more likely simply be missing, as wh-questions without auxiliaries are still the most frequent question type in Adam's data, even at the end of the investigated period.

Second, there are occasional examples (6) in Adam's data of overgeneralization of inversion (with $\mathrm{BE}$ ) in embedded clauses, also attested in data from other children. This seems to go against the micro-cue model. Similar findings are attested in Swiss German child data (Schönenberger, 200I) and in embedded declaratives in Norwegian (Westergaard \& Bentzen, 2007), argued in the latter to be due to economy of movement. Transporting this idea to the English data, it is possible that Adam has misinterpreted the cue for $\mathrm{V}_{2}$ in main clauses to be movement to a lower position than in the adult grammar $\left(\mathrm{Wh}^{\circ}\right.$ instead of $\left.\mathrm{Int}^{\circ}\right)$. Since embedded wh-clauses are considered to be bare WhPs in the syntactic model adopted 
here (see above), this tendency for economy of movement would cause the learner to infer that there Is inversion also in embedded contexts. This is obviously a perfectly possible grammar, since other varieties of English display this word order. This tendency for economy will be overridden by input in Standard English, and Adam apparently quickly reformulates the micro-cue to the adult version.

To conclude this section, I have argued that children's general targetconsistent word order in cases where there is micro-variation in the input may be accounted for by a model of micro-cues. These micro-cues enable children to make fine (linguistically relevant) distinctions and prevent them from making overgeneralization errors in syntax. But the micro-cues may also be responsible for delays in acquisition, seen e.g. in Adam's data, in that children make even finer distinctions than the adult grammar. For children to overcome such delays, input frequency must play a role. Unlike a constructivist account such as R\&P, however, I would argue that frequency is not by itself a cause for non-target behavior (see also Westergaard \& Bentzen, 2007).

\section{SUMMARY AND CONCLUSION}

In this paper, I have discussed the issue of usage-based vs. rule-based learning in relation to children's acquisition of word order in wh-questions in English and Norwegian. In my re-evaluation of previous work, I have questioned a generative parameter-setting approach and especially a constructivist usage-based approach, and based on some further data on different types of wh-questions, I have argued that neither can account for the Norwegian and English child data. The main finding of the investigation of the Norwegian data is that the children are perfectly able to make fine distinctions with respect to inversion at an early age, e.g. between long and short wh-elements or between main and embedded contexts. Furthermore, they do not seem to be paying attention to frequent word combinations in the input, both because of the high number of possible (and attested) combinations, as well as the fact that such combinations are not always imitated (in subject questions). A re-evaluation of the English data in $\mathrm{R} \& \mathrm{P}$ reveals that Adam also produces target-consistent word order in embedded questions and questions with long wh-elements. However, there are indications that inversion in Adam's grammar is only partly in place, as he makes a distinction with respect to type of wh-element (why vs. the rest) and type of verb (BE vs. auxiliaries). I also dispute R\&P's calculation of Adam's production in relation to the input.

The general conclusion is that it is difficult to analyze the Norwegian and English child data on word order in wh-questions without arguing that the children's production is the result of some rule-based process. More

$$
1048
$$


specifically, I have presented a cue-based approach to language acquisition which asserts that children must discover minor (linguistically relevant) distinctions in the input, called micro-cues. In the case of inversion, these reflect the fact that there is considerable variation across adult languages with respect to the elements involved; wh-element, verb and subject. The child data investigated also indicate that children are sensitive to these micro-cues from early on, as they are able to make the fine distinctions immediately. This may explain the generally conservative nature of the acquisition of syntax. To the extent that children produce non-targetconsistent forms, they typically have more restricted V2 grammars than adults, making even finer linguistically relevant distinctions. Thus, as the micro-cues prevent (over-)generalization, they are also responsible for children's non-target-consistent, but still principled, behavior for a certain period of time.

\section{REFERENCES}

Ambridge, B., Rowland, C. F., Theakston A. L. \& Tomasello, M. (2006). Comparing different accounts of inversion errors in children's non-subject wh-questions: 'What experimental data can tell us?' Journal of Child Language 33, 5 I9-57.

Anderssen, M. (2006). The acquisition of compositional definiteness in Norwegian. Doctoral Dissertation, University of Tromsø.

Bhatt, R. M. (2004). Indian English: syntax. In B. Kortmann, K. Burridge, R. Mesthrie, E. W. Schneider \& C. Upton (eds), Handbook of varieties of English 2: Morphology and syntax, гог6-30. Berlin/New York: Mouton de Gruyter.

Brown, R. (1973). A first language: The early stages. Cambridge, MA: Harvard University Press.

Clahsen, H., Penke, M. \& Parodi, T. (1 993/94). Functional categories in early child German. Language Acquisition 3, 395-429.

Chomsky, N. (1986). Knowledge of language: Its nature, origin and use. New York: Praeger Publishers.

DeVilliers, J. (I99I). Why questions? In T. L. Maxfield \& B. Plunkett (eds), Papers in the acquisition of wh: Proceedings of the Umass Roundtable, May I99o. Amherst, MA: University of Massachsetts Occasional Papers.

Diessel, H. \& Tomasello, M. (200I). The acquisition of finite complement clauses in English: A usage-based approach to the development of grammatical constructions. Cognitive Linguistics 12, 97-I4I.

Henry, A. (1995). Belfast English and Standard English. New York and Oxford: Oxford University Press.

Ingram, D. \& Tyack, D. (1979). Inversion of subject NP and Aux in children's questions. Fournal of Psycholinguistic Research 8(4), 333-4I.

Jordens, P. (I 990). The acquisition of verb placement in Dutch and German. Linguistics 28, I $407-448$.

Kroch, A. \& Taylor, A. (1997). Verb movement in Old and Middle English: Dialect variation and language contact. In A. van Kemenade \& N. Vincent (eds), Parameters of morphosyntactic change, 297-325. Cambridge: Cambridge University Press.

Kuczaj, S. \& Maratsos, M. (I983). Initial verbs of yes-no questions: A different kind of general grammatical category. Developmental Psychology 19(3), 440-44.

Lightfoot, D. (1999). The development of language: Acquisition, change and evolution. Malden, MA and Oxford: Blackwell.

Lightfoot, D. (2006). How new languages emerge. Cambridge: Cambridge University Press. 
Lightfoot, D. \& Westergaard, M. (2007). Language acquisition and language change: Inter-relationships. Language and Linguistics Compass I(5), 396-4I 5.

MacWhinney, B. (2000). The CHILDES Project: Tools for analyzing talk. 3rd ed. Vol. 2: The database. Mahwah, NJ : Lawrence Erlbaum Associates.

Poeppel, D. \& Wexler, K. (I993). The full competence hypothesis of clause structure in Early German. Language 69, I-33.

Poletto, C. \& Pollock, J.-Y. (2004). On wh-clitics and wh-doubling in French and some North Eastern Italian dialects. Probus 16, 24I-72.

Radford, A. (1992). The acquisition of the morphosyntax of finite verbs in English. In J. M. Meisel (ed.), The acquisition of verb placement: Functional categories and V2 phenomena in language acquisition, 23-62. Dordrecht: Kluwer.

Rizzi, L. (I 996). Residual verb second and the wh-criterion. In A. Belletti \& L. Rizzi (eds), Parameters and functional heads, 63-90. Oxford: Oxford University Press.

Rizzi, L. (200I). On the position 'Int(errogative)' in the left periphery of the clause. In G. Cinque \& G. Salvi (eds), Current studies in Italian syntax, 287-96. Amsterdam: Elsevier.

Roeper, T. (1999). Universal bilingualism. Bilingualism: Language and Cognition 2(3), I 69-86.

Roeper, T. (2007). What frequency can do and what it can't. In I. Gülzow \& N. Gagarina (eds), Frequency effects in language acquisition: Defining the limits of frequency as an explanatory concept, 23-48 [Studies on Language Acquisition]. Berlin: Mouton de Gruyter.

Rowland, C. F. \& Pine, J. M. (2000). Subject-auxiliary inversion errors and wh-question acquisition: 'What children do know?' Fournal of Child Language 27, I 57-8 I.

Rowland, C. F. \& Pine, J. M. (2003). The development of inversion in wh-questions: A reply to Van Valin. Fournal of Child Language 3o, I 97-2 I 2.

Rowland, C. F., Pine, J. M., Lieven, E. M. V. \& Theakston, A. L. (2003). Determinants of acquisition order in wh-questions: Re-evaluating the role of caregiver speech. Fournal of Child Language 3o, 609-635.

Santelmann, L. (1995). The acquisition of verb second grammar in child Swedish: Continuity of Universal Grammar in WH-questions, topicalizations and verb raising. $\mathrm{PhD}$ dissertation, Cornell University.

Santelmann, L., Berk, S., Austin, J., Somashekar, S. \& Lust, B. (2002). Continuity and development in the acquisition of inversion in yes/no-questions: Dissociating movement and inflection. Fournal of Child Language 29, 81 $3-42$.

Schönenberger, M. (200I). Embedded $V$-to-C in child grammar: The acquisition of verb placement in Swiss German. Studies in Theoretical Psycholinguistics. Dordrecht: Kluwer.

Snyder, W. (2007). Child language: The parametric approach. Oxford/New York: Oxford University Press.

Tomasello, M. (2003). Constructing a language: A usage-based theory of language acquisition. Cambridge, MA: Harvard University Press.

Tomasello, M. (2006). Acquiring linguistic constructions. In D. Kuhn \& R. Siegler (eds), Handbook of child psychology, 255-98. Hoboken, NJ: Wiley.

Vangsnes, Ø. A. (2005). Microparameters for Norwegian wh-grammars. Linguistic Variation Yearbook 5, I87-226. Amsterdam and Philadelphia: John Benjamins.

Van Valin, R. D. (2002). The development of subject-auxiliary inversion in English wh-questions: An alternative analysis. Fournal of Child Language 29, I6 I-75.

Vikner, S. (1995). Verb movement and expletive subjects in the Germanic languages. New York and Oxford: Oxford University Press.

Westergaard, M. R. (2003). Word order in wh-questions in a North Norwegian dialect: Some evidence from an acquisition study. Nordic Fournal of Linguistics 26(I), 8I-Io9.

Westergaard, M. (2008a). Verb movement and subject placement in the acquisition of word order: Pragmatics or structural economy? In P. Guijarro-Fuentes, P. Larranaga \& J. Clibbens (eds), First language acquisition of morphology and syntax: Perspectives across languages and learners, 6I-86 [Language Acquisition and Language Disorders 45]. Amsterdam: John Benjamins. 
Westergaard, M. (2008b). Acquisition and change: On the robustness of the triggering experience for word order cues. Lingua II8(I2), I 84I-63.

Westergaard, M. (2009). Microvariation as diachrony: A view from acquisition. Fournal of Comparative Germanic Linguistics $\mathbf{1 2}(\mathrm{I})$.

Westergaard, M. \& Bentzen, K. (2007). The (Non-)effect of input frequency on the acquisition of word order in Norwegian embedded clauses. In I. Gülzow \& N. Gagarina (eds), Frequency effects in language acquisition: Defining the limits of frequency as an explanatory concept, 271-306 [Studies on Language Acquisition]. Berlin: Mouton de Gruyter. 